\title{
Foreign Aid Transaction Costs: What Are They and When Are They Minimised?
}

\author{
Frieda Vandeninden and Elisabeth Paul*
}

\begin{abstract}
'Transaction costs' are commonly referred to in the recent literature on aid effectiveness. Aid transaction costs, however, have been neither consistently defined nor measured. This article defines aid transaction costs as all the economic costs associated with aid management that add no value to aid delivery. This enables the 'net' transaction costs that should be minimised to be identified. An analytical framework is then developed for assessing these costs. This allows the effectiveness of different aid modalities to be compared, according to the characteristics of the aid transaction. The article shows that the choice of aid modality should depend on these characteristics and, therefore, that the minimisation of transaction costs should not be an end in itself.
\end{abstract}

Key words: Transaction costs, aid effectiveness, aid modalities

\section{Introduction}

Since the 1990s, there has been a growing debate about the effectiveness of development aid. A wide body of empirical literature has been written about the impact of aid on poverty reduction and growth (Burnside and Dollar, 2000; Easterly et al., 2003). However, there is still no clear-cut conclusion as to the relative (in)effectiveness of aid: although most scholars agree that aid has surprisingly little impact on development, there is no consensual explanation for its ineffectiveness. For a long time, some economists have claimed that the major causes of aid ineffectiveness were weak institutional capacities and inappropriate policy environment in the recipient countries (Burnside and Dollar, 2000). However, as this hypothesis is very deterministic (it would imply that aid should be given only to recipient countries with 'good enough' policies if donors want it to be efficient), the international community and aid practitioners have also questioned existing aid-delivery mechanisms and aid modalities. In particular, some major problems associated with traditional co-operation instruments - namely, projects and structural adjustment programmes - have been identified. ${ }^{1}$ Major criticisms of these modalities deal with the lack of coherence between donors' policies as well as with recipient countries' own policies and systems; the fragmentation and duplication of donor projects; the lack of ownership and leadership by recipient countries; and the lack of long-term effects of projects on local institutions' capacities (World Bank, 1998).

* University of Liège, Boulevard du Rectorat 7, Liège 4000, Belgium (frieda.vandeninden@governance. unimaas.nl).

1. See Foster and Leavy (2001) for a review of the financial aid instruments and World Bank (1998) and Bourguignon and Sundberg (2007) for the debate on aid effectiveness. 
To respond to these criticisms, what can be described as a new aid paradigm has been built around a set of pillars: partnership and participation, ownership of development strategies by domestic constituencies, alignment of donors on domestic policies and systems, co-ordination and harmonisation between donors, results orientation and mutual accountability (Paul, 2002). The development community and a number of recipient countries have committed to respecting these principles in delivering and managing aid by signing the Paris Declaration on Aid Effectiveness in 2005, and have confirmed that willingness by signing the Accra Agenda for Action in 2008 (see http://www.aideffectiveness.org).

The new aid paradigm and its pillars are notably supposed to enhance aid effectiveness by reducing the costs arising from multiple and unco-ordinated donor practices (OECD, 2003). Aid practitioners often refer to these so-called aid transaction costs to explain the poor aid effectiveness and to justify the necessity to change the aiddelivery system. As pointed by Acharya et al. (2006: 7), '[t]here are very strong reasons to believe that, all other considerations aside, aid often underperforms because it flows through too many institutional channels. This generates high transactions costs within each recipient nation, and so reduces the value of aid.' This issue is becoming more and more problematic due to rising aid fragmentation (Knack and Rahman, 2004).

Thus the reduction of aid-transaction costs has been one of the major motivations behind the shift in the aid-delivery system (see Section 2), and many efforts have been made to reduce them, implicitly assuming that this would improve aid effectiveness. As a matter of fact, many international debates on developmental assistance have centred on the issue of transaction costs. It has often been agreed that high transaction costs may cause Official Development Assistance (ODA) to underperform in several respects: (i) through influencing the volume of aid delivered, by discouraging donors and governments from entering into agreements, and reducing disbursement rates; (ii) through reducing aid efficiency, by consuming donor and government resources that could be otherwise employed and misallocating the resources made available under aid agreements; and (iii) through reducing aid effectiveness, by encouraging donors and recipient governments to allocate resources to activities that do not address development priorities and, in some cases, undermine institutional development goals (UNDP and DFID, 2000, §27).

Yet, we have not found any satisfying definition, typology or measurement of aid transactions costs in the literature. Quoting Acharya et al. (2006: 7) '[n]o one has ever measured them. It is not clear that they are measurable.' Definitions found in the literature rest on no theoretical grounds and may actually lead to misinterpretations. The first point of this article is thus to review the current use and definitions of aid transaction costs.

The article intends to address two issues. After showing that the notion of aid transaction costs in the literature is quite indistinct, our first aim is to put forward a satisfying definition of these costs. To do so, we have chosen to examine the aid transaction from the perspective of Transaction Cost Economics (TCE) (Section 3). In doing so, we show that account should be taken of the characteristics of the aid transaction before arguing that one particular aid modality could reduce transaction costs. The theoretical background exposed in Sections 3 and 4 allows proposing a definition that avoids possible confusion between costs of different kinds. 
The second issue addressed is whether a change in aid modality is worthwhile, in terms of reducing transaction costs. As shown in Section 4, the transaction characteristics should be taken into account before arguing that one aid modality is more efficient than another. We therefore develop a simple model that relates costs and different characteristics, and enables assessing whether one modality should be replaced by another, according to the specific characteristics of the aid transaction considered. Finally, Subsection 4.3 discusses the minimisation of transaction costs and argues that this should not be an end in itself, because aid effectiveness does not necessarily imply low transaction costs.

\section{Transaction costs viewed by aid practitioners}

The international community is now generally aware of the problem of transaction costs. For instance, the Monterrey Conference of 2002 specifically called on development-co-operation agencies to intensify their efforts to 'harmonize their operational procedures at the highest standard so as to reduce transaction costs and make ODA disbursement and delivery more flexible' (United Nations, 2002). The Rome Declaration on Harmonization (see www.aideffectiveness.org) signed in 2003 states that: 'We in the donor community have been concerned with the growing evidence that, over time, the totality and wide variety of donor requirements and processes for preparing, delivering, and monitoring development assistance are generating unproductive transaction costs for, and drawing down the limited capacity of, partner countries' (High Level Forum, 2003). The Paris Declaration on Aid Effectiveness notably encourages donors to untie aid because it 'generally increases aid effectiveness by reducing transaction costs for partner countries' (High Level Forum, 2005: §31), and notes that '[e]xcessive fragmentation of aid at global, country or sector level impairs aid effectiveness. A pragmatic approach to the division of labour and burden sharing increases complementarity and can reduce transaction costs' (ibid.),

Recent efforts to improve aid effectiveness rest on improving donor co-ordination, harmonisation and alignment in national systems, as well as on concentrating and delegating aid, so as to reduce aid transaction costs (for example, OECD, 2003, 2006; EuropeAid, 2007). To this end, the Development Assistance Committee (DAC) of the Organisation for Economic Co-operation and Development (2003) suggests that, as a first step, donors should simplify and harmonise their procedures, align them on partner systems, and be more transparent. Then, additional ways of reducing transaction costs could be streamlining conditionality, rationalising fiduciary assessments, aligning processes, tapping the potential of joint donor frameworks, and timing disbursements to facilitate the smooth execution of budgetary payments (OECD, 2006: 29-31). Concretely, transaction costs may also decrease when donors channel aid funds through national procedures, especially through sector-wide approaches (SWAps) and budget support (OECD, 2003, 2006; EC, 2007).

From the above examples, one observes that the commitment of the international community to try to reduce transaction costs is undeniable. However, one should question more deeply what is intended to be reduced. What are transaction costs actually? How are they measured? Should they be reduced, and how? We first turn to 
the grey literature issued from aid practitioners to assess their perspective on the matter. It is apparent that there is a lot of confusion and no agreement over a common definition of aid transaction costs. Moreover, measuring aid transaction costs appears to be an unachievable challenge. Then, we shall discuss what trends in transaction costs are expected to occur with a shift in aid modality (namely, from project to programme approach), even if evidence is mixed.

\subsection{Tentative definitions of transaction costs}

Aid practitioners commonly refer to transaction costs, but without defining them precisely. For instance, in its Guidelines on Harmonising Donor Practices for Effective Aid Delivery, the Development Assistance Committee of the OECD (2003: 114) identifies two types of costs in the aid relationship:

- 'Administrative costs of aid: this includes the costs of transferring aid from donors to recipients and the costs of planning aid and monitoring its progress and impact.

- Costs of forgone development of partner institutions: the efficiency losses (due to lowered morale and initiative and loss of scarce skills to donors' parallel structures) associated with low ownership by government, when donors bypass government. The forgone development of partner institutions raises future transaction costs and encourages donors to continue working through parallel structures. ...'

In a footnote to its 'Guidelines on the Programming, Design and Management of General Budget Support', the European Commission (2007: 19) states that ' $[\mathrm{t}$ ]ransaction costs may be defined as the extra costs - beyond that of the aid itself - of delivering aid. These costs may be borne by the recipient, the donor, or by both. It may cover, for example, the money, time, inconvenience of identifying, negotiating, implementing, monitoring and evaluating aid delivery.'

In its Guidelines on Support to Sector Programmes, EuropeAid (2007: 27) provides some further explanations for understanding transaction costs. It specifies that:

[t]ransaction costs occur at all stages of the aid management cycle, from the initial negotiation of aid through to disbursement, implementation (including procurement, construction, etc), and monitoring of the activities it finances. There may also be conversion costs in moving from one financing instrument to another and different elements of risk for different types of transaction. ... Transaction costs are not a pure efficiency loss: the same activities that embody transaction costs may also have positive benefits (for example, learning from working groups, mitigating risks through fiduciary safeguards). Transaction costs are difficult to quantify, and there is much observer bias in their assessment ...

In a background paper for the World Development Report, Dyer (2005) assesses transaction costs in the education sector in Tanzania. She puts forward some working 
definitions and distinguishes different kinds of aid transaction costs: (i) administrative costs, which refer largely to the costs in terms of meetings, reports, and arrangements for release and reporting of money and so on, which take up donor and government time; (ii) tying costs, which are not addressed explicitly in her paper, since they are negligible in comparison with other transaction costs; and (iii) fiscal costs, relating to financial flows and the use of different aid modalities.

Recognising that the concept of aid transaction costs has hardly been defined in the literature, Acharya et al. (2006: 7) make a conceptual contribution to the debate by suggesting that these transaction costs can be usefully divided into two categories: (i) direct transaction costs, that essentially take the form of the absorption of the scarce energies and attentions of relatively senior government staff by a multitude of projects, each of them requiring separate negotiation and distinct management and reporting requirements; and (ii) indirect transaction costs, that take the form of the dysfunctional bureaucratic and political behaviour that is stimulated by aid proliferation (for example, internal brain drain at the expense of government agencies, topping-up, distortion in the choice of projects, excessive expenditure on technical assistance, competition between donors inducing 'hoarding' of information, lack of a sense of responsibility for the outcomes of aid, etc.).

A more recent tentative definition of aid transaction costs has been made by Lawson (2009). He defines them as 'the costs necessary for an aid transaction to take place but which add nothing to the actual value of that transaction'. He identifies three cost categories: search costs (to identify partners and potential project or programme), bargaining and decision costs (to negotiate the financial agreements and expected outcomes) and policing and enforcement costs (to respect the monitoring and execution requirements imposed by donors, to monitor donors' commitment and to supervise the project or programme conditions).

\subsection{Tentative measurement of aid transaction costs}

As there is no agreement over a common definition of aid transaction costs, the few tentative measurements of these costs have not succeeded. Aid transaction costs are particularly difficult to quantify, particularly since there is much observer bias in their assessment (EuropeAid, 2007: 27). Generally speaking, transaction costs are not usually effectively measured, but rather estimated - using proxy indicators to do so.

For instance, a study undertaken in Vietnam, which originally had been conceived in order to quantify the transaction costs of managing aid through detailed survey questionnaires and interviews, had to acknowledge that: (i) it is very difficult to gather quantitative information on transaction costs, partly because there is no tested methodology available to measure them, and partly because availability of data was more limited than expected; and (ii) measuring transaction costs in itself incurs unacceptably high transaction costs (UNDP/DFID, 2000). Therefore, the approach adopted had to focus more on the qualitative aspects of transaction costs, and the debate moved on from what the transaction costs are to where they are incurred in the system, why they are incurred, and what could be done to reduce them.

Similarly, Dyer (2005) attempted to quantify transaction costs, without success. She noted that almost all those interviewed complained about the high level of 
transaction costs, but no one interviewed is actually trying to quantify them. She did, however, report a number of suggestions as to how transaction costs might be measured, including proxies such as the number of reports, missions, meetings, separate legal instruments, separate audit requirements, and number of staff (particularly sector specialists) required by donors.

Amis et al. (2005) came to the conclusion that when the initial focus of trying to provide an overall quantitative measurement of transaction costs proved to be impractical, the emphasis shifted towards a more relative approach, ranking burdens of aid as perceived by recipient officials. This is the approach now used by the OECD's DAC (2005).

Watt (2005) adopted a relative approach and focused on measurement tools such as number of joint missions, numbers of donors that participate in the SWAp under study. Jobin also proposes an evaluation methodology for comparing transaction costs associated with two or more aid modalities, especially the 'partnership' one. As he mentioned, 'Since TCs [transaction costs] are not directly measured but, rather, estimated (using the critical dimensions of a given transaction as proxies), it is sufficient to $\bullet$ nd a signi $\bullet$ cant relationship and variation between estimated TCs and a productivity index for a given partnership' (Jobin, 2008: 442). To our knowledge, his methodology has neither been applied nor tested.

\subsection{Transaction costs and aid modalities}

Notwithstanding definition and measurement problems, as the OECD (2003: 114) concludes, 'the objectives for aid costs are i) they should be low, and ii) they should result from carrying out administrative, planning and monitoring tasks in a way that helps the development of efficient systems for managing resources in partner countries.' Different ways of managing aid may distribute transaction costs differently (for example, between international partners and government, between country offices and HQs, between finance ministries and sector ministries) (EuropeAid, 2007: 27). A series of good practices have been identified so as to reduce transaction costs, both at the macro level (such as improving medium-term resource planning by the government, and ensuring donors support this process; improving the quality of public expenditure information; improving donor co-ordination; consolidating projects) and at the projectcycle management level (for example, improving the project identification and appraisal process by government, and ensuring support for this process by donors; addressing problems with project implementation, monitoring and evaluation which are partly caused by the project management unit structure; standardising procedures between government and donors; standardising procurement procedures and monitoring requirements) (UNDP/DFID, 2000).

As already mentioned, the project approach to development co-operation has been notably criticised for encompassing very high transaction costs, all the more since the aid architecture is becoming more and more fragmented. In response to that criticism, it has been suggested that the so-called programme approach, ${ }^{2}$ especially as materialised

2. The programme approach or programme-based approach (PBA) has been defined by the Learning Network on Programme Based Approaches (LENPA) as 'a way of engaging in development co-operation 
through sector-wide approaches and budget support, could help to reduce transaction costs. However, this still has not been empirically established in any systematic way (Killick, 2004: 19) and anecdotal field experience is mixed. Martinez (2006) concludes that, as a result of the health SWAp in Mozambique, some transaction costs have been reduced, but others have either remained unchanged (those linked to disease interventions) or even increased (those linked to review processes and to the SWAp forum and its working groups). In addition, several donors continue to field separate missions for each of the sectors, which further increases transaction costs. He mentions that a recent report estimated no less than 143 missions to Mozambique by the main donors providing budget support during 2004-5, plus World Bank missions. Vandeninden (2005) also tried to evaluate the evolution of transaction costs in the health and education sectors in Mali since the introduction of a SWAp, mainly through qualitative data. Her results are mixed as well: some costs seem to have been reduced, but others have increased and new costs have appeared. The OECD (2003: 116) also notes that, in Tanzania, many donor representatives have expressed their concern about increasing transaction costs on their side due to the development and monitoring of SWAps and similar co-ordinated aid arrangements; however, these increased transaction costs should be compared with savings that may occur elsewhere.

As for budget support, the use of domestic financial-management systems is expected to reduce transaction costs. However, if budget support is coupled with more complex management requirements and demands by donors for deeper reform and better reporting, transactions costs may change very little (OECD, 2003: 122). DFID reckons that:

[a]lthough the transaction costs of budget support are likely to be higher in the short term, as new ways of working between governments and donors are established, net transaction costs should be lowered over the medium term. This is because donors should be using the government's own reporting and accounting systems to monitor progress, rather than negotiating, managing and monitoring literally thousands of projects. ... Preliminary evidence from Uganda indicates that transaction costs may have increased in the short run, as donors have yet to embed new ways of interacting with each other and with Government. However, there are reasonable prospects of a reduction in the medium term. (DFID, 2004:7)

In fact, a reference evaluation of partnership global budget support (PGBS) performed in seven countries confirms that:

[a]lthough the high-level negotiation and monitoring costs of PGBS are often perceived as onerous, there are large transaction cost savings for partner

based on the principle of co-ordinated support for a locally owned programme of development, such as a national poverty reduction strategy, a sector programme, a thematic programme or a programme of a specific organisation'. PBAs share the following features: leadership by the host country or organisation; a single comprehensive programme and budget framework; a formalised process for donor co-ordination and harmonisation of donor procedures for reporting, budgeting, financial management and procurement; efforts to increase the use of local systems for programme design and implementation, financial management, monitoring and evaluation (Lavergne and Alba, 2003; quoted in OECD, 2006: 37). 
countries during the implementation of PGBS-financed activities. The extent of transaction cost savings has been limited by the scale on which other modalities have continued in parallel. (IDD and Associates, 2006: S5)

\section{Aid transaction costs from the perspective of Transaction Cost Economics}

From the Sections above, we understand that the analysis of aid transaction costs has so far lacked a solid theoretical background. Existing definitions are various and vague, and do not enable precise identification of the costs. No effective methodology has been developed to measure them, and available evidence over their evolution is mixed. One also understands that the shift to programme approaches has partly been justified by an intention to reduce aid transaction costs. In order to be able to propose a generic definition of these costs and an analytical framework to evaluate when a change in aid modality is desirable, we first present the economic theory that seems most relevant to analyse our issue - that is, transaction cost economics. As a matter of fact, aid delivery is a transaction per se: donors transfer money and other inputs to a partner country and, in exchange, they expect to observe some results (such as poverty reduction, education, vaccination, etc.). Hence, transaction cost economics may be a useful tool for understanding how these costs can be minimised. We first introduce the main concepts of transaction cost economics, and then analyse aid modalities in terms of governance structures.

\subsection{Transaction cost economics}

This stream of economic theory was mainly developed by Oliver E. Williamson in the 1970s, and then by Douglass North in the early 1990s. The theory aims to find the best way to organise a transaction of goods or services between two economic agents (Williamson, 1993: 16). The theory is grounded on the principle that the structure of governance chosen for the transaction should minimise transaction costs, in view of the fact that each transaction differs according to various characteristics.

Transaction cost economics also relies on two main behavioural hypotheses that explain why the costs occur. The first hypothesis is bounded rationality, such that economic agents cannot predict precisely how the transaction will evolve. It implies that every contract is inherently incomplete. The second one is the risk of opportunism: because of the contract's incompleteness, there is a risk that agents involved in the transaction take profit from the imperfect distribution of information. As a consequence of these two hypotheses, when a transaction takes place, the agents involved bear some costs for coping with contract incompleteness and the risk of opportunism. In the context of aid-recipient countries, these hypotheses may be interpreted in terms of corruption, sub-optimal behaviours (for example, implementation of programmes that do not address developmental priorities) and constraints in the relationship between donors and recipients (unnecessary monitoring procedures, conditionality, etc.).

Transaction cost economics reckons that various structures of governance may be preferred, depending on the characteristics of each transaction. It distinguishes between three types of characteristics. (i) Asset specificity refers to whether the transaction 
concerns non-standard goods that require specific investments that cannot be easily reused for other transactions (for example, producing a specific item can require the construction of a machine that will only produce this item) so that if the transaction ceases, the investment is lost. The impact of this characteristic on the choice of governance is obvious: when asset specificity is high, both parties should want to lead the transaction to a positive end - otherwise, the investments in the specific asset will be lost or devalued. In the context of foreign aid, investments in specific assets are probably high, because both recipient government and donors have to invest in the aidmanagement process (for example, staff training, technical assistant provision, development of financial and reporting procedures, monitoring, etc.). (ii) Uncertainty: as information is always incomplete, agents cannot predict other agents' performance. Following the principal-agent theory, information incompleteness can take the shape of moral hazard (one agent cannot assess the other agent's effort/actions) or asymmetry (one agent has more information than the other). Because of such lack of transparency, the principal (donor) does not know precisely how the agent (recipient government) allocates and manages aid. Uncertainty increases transaction costs since it incites both parties to negotiate complex contracts and/or augment controlling costs. (iii) Frequency: as one may expect, the more frequently the transaction takes place, the more easily the costs of setting formal governance structures are recovered.

\subsection{Aid modalities and governance structures}

Relying on the above-mentioned behavioural hypotheses and transaction characteristics, transaction cost economics intends to design structures of governance that minimise transaction costs. Figure 1 presents an analytical framework that shows which governance structure is most adapted, depending on transactions characteristics. As explained below, we apply that framework to aid delivery and view aid modalities as governance structures. This enables us to analyse what aid modalities are preferred, according to the transaction characteristics.

\section{Figure 1: Foreign aid modalities and governance structures}

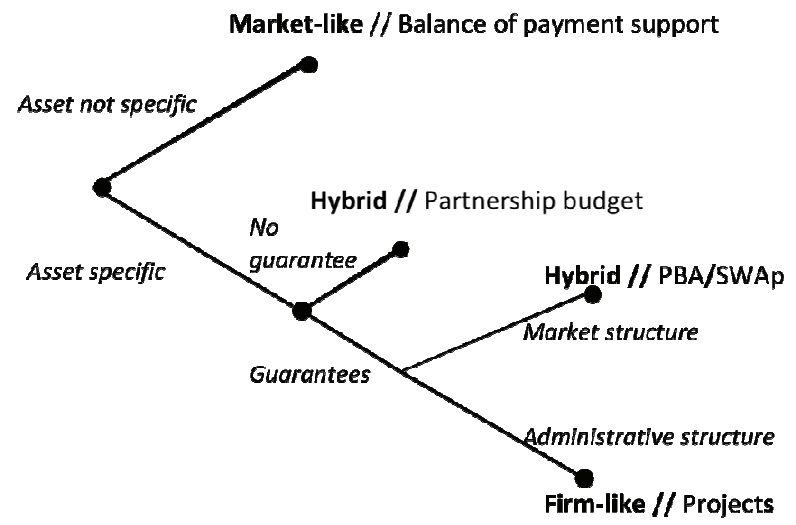

Source: Author's adaptation of Williamson (1993: 52). 
Figure 1 above is inspired by Williamson (1993: 52) and distinguishes three governance structures: the market, the firm, and hybrid structures, which are optimal according to the characteristics of the transaction (asset specificity, uncertainty and frequency). Williamson interpreted it as follows. Transactions taking place on the market generally concern non-specific goods. In fact, standard products provide both parts of the transaction with sufficient protection against opportunism, as the provider can easily be replaced if he does not respect his commitments. Thus, building a detailed contract that foresees the transaction's evolution is not necessary. On the contrary, for those goods that have a very high level of asset specificity, both parts of the transaction have to protect themselves against the risk of transaction cancellation which would imply important 'sunk costs' (Williamson, 1993: 16). When uncertainty and/or transaction frequency are very high, it can be preferable to internalise the transactions into one economic unit: the firm. Yet, inevitably, such a structure of governance is costly to set up and entails management costs, which should not exceed the expected gains in terms of transaction costs. Between these two extreme cases (the market and the firm), the third case deals with those goods that have a relatively high level of specificity and thus require a contract stipulating the transaction expectations (nature of the item, quality, shipping details, etc.), but are not subject to frequent transactions, so that the costs induced by internalising the transaction into a firm would not be recovered. In this case, one would rather set up a contract that still encompasses costs, but that does not entail firm-management costs. So-called hybrid structures of governance may therefore be relevant. They present some of the characteristics of both the market and the firm. In practice, they take the form of all other types of contracts between two or more parties.

Aid delivery, as with any transaction, generates some costs. The aforementioned rationale can therefore be applied to the aid-delivery system, where the intended use of aid funds by donors may be viewed as asset specificity, and where aid modalities may be viewed as governance structures.

Aid transfers that are not associated with specific requirements with regard to the use of funds, and therefore do not entail specific management tools (conditionality, reform measures, indicators, monitoring processes, etc.) can easily be managed through a market-like governance structure; this situation can be assimilated with the balanceof-payment support. However, donors - and governments - often attach a value as to how aid funds are used, and are ready to invest in further specific assets (conditionalities, experts, monitoring systems, etc.) to prevent aid from being misallocated by opportunism. According to transaction cost economics, such asset specificity associated with aid entails the non-market governance structure being optimal to minimise transaction costs. Following our analytical framework outlined in Figure 1, three cases may be encountered. When donors do not specify how aid funds should be allocated (so that the recipient government decides on how to use them) and therefore do not set up a specific 'guarantees' system, a hybrid contract appears to minimise aid transaction costs. When applied to our purpose, this situation can be assimilated with partnership budget support. When donors stipulate how the money should be allocated and frequently interact with the government on related matters, the corresponding hybrid structure of governance appears to be the programme-based approach (PBA), especially the sector-wide approach (SWAp). Finally, when donors 
have such precise requirements regarding the use of aid funds that they prefer to manage them themselves, they can set up a firm-like hierarchical structure in order to control the transaction, under the form of a project.

This analytical framework thus gives some theoretical prediction of which governance structure - or aid modality - minimises aid transaction costs, according to the transaction characteristics. We shall rely on it in order to determine when a change in aid modality is worthwhile. Indeed, different aid management structures are associated with different transaction costs, but the question as to which is the most appropriate is not straightforward, since it depends on country specificities and the value of different aid characteristics. For instance, it is often argued that programme aid and budget support should be associated with less transaction costs than a multiplication of projects, as they promote donor co-ordination, harmonisation and alignment. However, this has not been formally proved, all the more since they entail new types of costs in the form of co-ordination costs, development of a common monitoring system, capacity-building, etc. As Killick (2004: 19) points out, 'the superiority of programme aid in this respect remains only a hypothesis because it rests on a presumption of the comparative costs of the respective aid modalities, which has not, so far as is known, been empirically established in any systematic way'. In order to assess whether one modality generates fewer costs than others, we hereafter extend the intuitions of transaction cost economics into a formal model. Our aim is thus to identify which modality is preferred - in term of cost minimisation - according to the aid transaction's characteristics. In other words, we aim to assess whether a change in aid modality is worth it in order to reduce transaction costs. Before that, we start by better defining aid transaction costs by using the background of transaction cost economics, as addressed in Section 4.

\section{Defining and estimating aid transaction costs}

\subsection{Aid transaction costs: what they are, what they are not}

As already mentioned, there is no universal definition of aid transaction costs. A narrow vision can restrict them to 'direct transaction costs' (Acharya et al., 2006) or 'administrative costs of aid', including only the 'costs of transferring aid from donors to recipients and those of planning aid and monitoring its progress and impact' (OECD, 2003: 114). However, most authors agree on the fact that aid transaction costs encompass a much broader reality.

On the theoretical side as well, the definition of transaction costs is elusive (Allen, 1999). For example, R. Coase, known as the pioneer of transaction cost economics (TCE), never actually used the term transaction cost explicitly in his first major article ('The Nature of the Firm', 1937). He was rather referring to general concepts such as 'the costs of using the price mechanism' or 'the cost of carrying out a transaction by means of an exchange on the open market'. Any transaction generates such costs because, as Coase (1961: 15) explains, '[i]n order to carry out a market transaction it is necessary to discover who it is that one wishes to deal with, to inform people that one wishes to deal and on what terms, to conduct negotiations leading up to a bargain, to 
draw up the contract, to undertake the inspection needed to make sure that the terms of the contract are being observed, and so on'. One of the first appearances of the term 'transaction costs' is to be found in Arrow (1969: 48), who defined transaction costs as 'the cost of running the economic system'. Williamson (1985: 19) then compares the transaction costs to the frictions in physical science. They are all the 'extra costs' generated from market imperfections. Even if the concept of transaction cost is defined quite vaguely, it still seems clear from the above that transaction costs are sunk costs, and differ in that respect from production costs.

We believe that this distinction between transaction and production costs is critical in order to reach a satisfactory 'economic' (rather than general) definition of aid transaction costs. ${ }^{3}$ In fact, some activities generating so-called transaction costs (for example, donor-government co-ordination meetings) also generate positive externalities such as learning from working groups, mitigating risks through fiduciary safeguards (EuropeAid, 2007: 27), bringing about additional technical expertise for national policies, trust and capacity-building, etc. Such transaction costs may be actually viewed as 'investment' costs and should not be confused with 'net' or 'sunk' costs emanating from the mere transfer and management of aid that encompass efficiency losses. Let us note from the start that most aid modalities are associated with some investment costs, but that the latter are probably higher when they are run on a large scale - such as PBA. Therefore, we propose to distinguish between gross and net transaction costs, in the following way:

$\mathrm{GATC}=\mathrm{IC}+\mathrm{NATC}$

where GATC is Gross Aid Transaction Costs; IC: Investment Costs; and NATC: Net Aid Transaction Costs.

According to that distinction, we propose to define net aid transaction costs as all the economic costs associated with aid management that do not add any value to the aid transaction. It is noticeable that only the net transaction costs reduce aid effectiveness and should therefore be minimised (see below). In fact, assessing the effectiveness of aid delivery requires looking at the final aid envelope available for the production of a developmental programme - that is, the total amount of aid minus net transaction costs.

$\mathrm{NAV}=\mathrm{GA}-\mathrm{NATC}$

where NAV is Net Aid Value; and GA: Gross Aid.

What we called aid investment costs (which may erroneously be commonly termed transaction costs) may actually increase the net aid value, because they contribute to producing positive externalities. These investment costs may improve information, help build common knowledge, systems and trust, and therefore reduce uncertainty and contribute to decreasing the net transaction costs for future transactions.

The economic meaning of aid transaction costs deserves more precision. Regarding the nature of costs, it goes without saying that transaction costs are not

3. Thus we fully agree with Lawson (2009) who specifies that transaction costs 'add nothing to the actual value of that transaction'. 
merely financial, but should be viewed as opportunity costs (that is, the value of the best alternatives that have been given up for the utilisation of a particular resource). They thus encompass the value of time, perverse effects on civil servants' behaviour, missed opportunities in terms of resource allocation, etc. Besides, Transaction Cost Economics rests on the assumption of limited rationality and opportunism, which lead to informational imbalances and are therefore very similar to the hypothesis of incomplete information in the principal-agent theory. The aid delivery system is indeed characterised by a chain of principal-agent relationships subject to information asymmetry (Martens et al., 2002; Paul, 2006). For instance, donors may be viewed as principals delegating tasks (for example, the realisation of a project or developmental programme) to the recipient government (viewed as the agent); other principal-agent relationships may also be identified in the aid delivery system, notably between donor agencies' main office and country offices, the Cabinet or Ministry of Finance and sector agencies, etc. Within each principal-agent relationship, the acting agent is often better informed than its principal, certainly regarding the working environment and its own effort or characteristics. The fungibility of aid funds further complicates the informational problem and means that donors cannot be sure that their funds have effectively been used for the intended purpose, unless they have a view of the whole spending programme of the government. ${ }^{4}$ These informational imbalances are known to lead to so-called adverse selection and moral hazard problems that create additional costs for the principal. In the context of aid management, a major type of agency cost encountered deals with all the costs associated with the additional controls and incentives set up by donors in order to induce recipient agents into acting in the desired way (for example, conditionality, financial controls and reporting). Another type of cost considered in the principal-agent literature is the economic cost of distortions from an ideal, perfect information-resource allocation; this relates, for instance, to overinvestment in some sectors or regions preferred by donors. Our definition of aid transaction costs allows taking account of such agency costs.

In concrete terms, there are different varieties of aid transaction costs, which may be differentiated according to several classification criteria, as detailed below.

- Timing of cost occurrence. According to Williamson (1985), there are two kinds of transaction costs: (i) ex-ante costs of drafting, negotiating, and safeguarding an agreement; these costs can be further divided into search costs and contracting costs; and (ii) ex-post costs of haggling, governance, and bonding to secure commitments; these costs can also be divided into monitoring and enforcement costs. In practice, aid transaction costs may occur at three stages of aid delivery: ex-ante (identification, negotiation and programming of aid programmes), during implementation (financial transfers, ongoing donor-government dialogue, project-management unit, procurement, monitoring), or ex-post (specific audits and evaluations).

4. The problem of aid fungibility arises when foreign aid earmarked for particular sectors is substituted for spending that recipient governments would have undertaken anyway, so that the aid funds are used to relax the government's budgetary constraint. Research shows that aid is fungible, at least in certain countries and sectors (Devarajan and Swaroop, 1998). 
- Who bears the costs? Aid transaction costs can be borne by donors and recipients. In the first case, they decrease the amount of resources that can be transferred to partner countries, and in the second case, they consume domestic resources that could have been valuable for alternative uses.

- Net versus gross costs. As already mentioned, we have to distinguish the mere efficiency losses - the net costs - from the gross costs that also encompass investment costs. The latter produce some positive externalities on the transaction (improving co-ordination, information, trust and capacity-building) and are expected to foster a decrease in future net transaction costs over the medium run.

\subsection{Estimating aid transaction costs}

As noted above, precisely measuring transaction costs requires a lot of quantitative and qualitative data and still remains a challenge. Most authors have attempted to evaluate their evolution using some proxy indicators and/or interviews. ${ }^{5}$ However, this methodology does not seem to work very effectively because it lacks a theoretical background enabling identification of what should and should not be reduced. Indeed, as already mentioned, some 'investment' costs associated with aid management actually help to decrease net transaction costs. Moreover, one should also be aware that the transaction costs incurred are related to the transaction's characteristics.

The simple model developed here shows that cost minimisation, and henceforth the choice of an aid modality, depends on the transaction's characteristics. It enables the following crucial question to be answered: when is a change in aid modality worthwhile?

Let the index $r$ stand for the recipient government, and $d=1, \ldots, n$ for the $n$ donors. We first specify transaction costs over one period $t$. The recipient government and each donor bear different transaction costs according to the transaction's characteristics. It is important to note that a number of factors influence the level of transaction costs: the number of donors active in the country and their degree of coordination, harmonisation and alignment over the recipient government's procedures; but also some characteristics that can be related to TCE theory and more specifically to Figure 1: the governance system in the recipient country (which influences the degree of uncertainty), and donors' possible specifications over the indented use of funds (which relates to asset specificity), such as the frequency of transactions (see below). Let us also recall that, following equation (1), we distinguish pure efficiency losses (NATC) from investment costs (IC).

The first step to understanding how to choose an optimal aid modality is to identify the links between the Gross Aid Transaction Costs (GATC) and the different characteristics of the transaction over a single period. The GATC $\left(G A T C_{r}\right.$ and

5. This exercise is beyond the scope of this article, which is limited to putting forward a more accurate conceptual framework for comparing transaction costs between different aid modalities. For more indications on how to measure transaction costs, see, for instance, Jobin (2008), who proposes a number of evaluation questions as well as a transaction-cost measurement framework based on surveys aimed at asking interviewees to assess different dimensions of transactions. Lawson (2009) also proposes some measurement tools and models of questionnaires. 
GATC $_{\mathrm{d}=1, \ldots, \mathrm{n}}$ for the recipient government and donors respectively) are the sum of investment costs - which are a function of the degree of harmonisation between donors, among other country-specific factors that are not incorporated in the model ${ }^{6}-$ and net transaction costs - which are a function of the degree of uncertainty and the level of asset specificity. Note also that donors are likely to be heterogeneous, so that, from the government's perspective, different donors will be associated with different costs. Let us define:

On the recipient government's side,

$$
G A T C_{r}=\sum_{d=1}^{n}\left[I C_{r, d}(h)+N A T C_{r, d}(s, u, h)\right]
$$

On the donors' side,

$$
G A T C_{d=(1, \ldots, n)}=\sum_{d=1}^{n}\left[I C_{d}(h)+N A T C_{d}(s, u, h)\right]
$$

So that the (total) gross aid transaction cost (GATC) for period $t$ is the sum of recipient and donors' costs:

$$
G A T C=G A T C_{d=1, \ldots, n}+G A T C_{r}
$$

where $s$ represents the level of asset specificity, $u$ the degree of uncertainty and $h$ the degree of harmonisation between donors, with $h=1$ if they fully harmonise their procedures and $h=n$ if there is no harmonisation at all. In fact, if harmonisation is perfect, it is like all donors forming a single donor.

This model is further specified to render the following characteristics. For both donors and recipients, NATCs are an increasing function in $s(\delta N A T C / \delta s>0)$. In fact, when donors have specific requirements about how aid should be allocated, they need to build a 'guarantees' system to ensure aid earmarking, which increases transaction costs. If donors align their aid on the recipient government's policies and systems, asset specificity decreases to zero, which in turn decreases NATCs. The same relationship applies to the degree of uncertainty: the more information asymmetry there is between donors and the recipient country, the more donors require guarantees, which increases NATC $(\delta N A T C / \delta u>0){ }^{7}$

The degree of harmonisation between donors also influences transaction costs. Logically, the more donors are harmonised, the less time-consuming day-to-day interaction with them is for the government $(\delta N A T C r / \delta h<0)$. But usually, all the necessary prerequisites for harmonising donor practices (notably in the context of a PBA) incur investment costs, for instance to create special financing and monitoring

6. Investment costs depend mostly on harmonisation as the more donors are harmonised, the less costs they impose on the recipient country. However, at constant harmonisation level, investment costs could be higher in countries where initial conditions are worse than in others (for example, a recipient country with very poor institutional capacities and a lot of fragmented donors). But in order to keep the model simple, we consider investment costs as a function of harmonisation only.

7. This assumption is supported by Jobin (2008: 452) who provides numerous references indicating that trust among partners plays a critical role in partnership performance, and that trust can reduce transaction costs. 
procedures and/or improving national ones, that may lead to an important (non-linear) 'jump' in ICs. Moreover, day-to-day co-ordination is also demanding for both donors and government, and the effect of harmonisation over NATCd is less obvious to assess, and probably differs from one donor to another. Figure 2 gives an idea of the evolution of transaction costs with the degree of harmonisation. In this setting, harmonisation decreases NATCs to a certain extent, but it should not be pursued beyond a certain point where the gain in NATC reduction no longer balances necessary investment costs.

\section{Figure 2: Likely evolution of transaction costs with harmonisation (static model)}

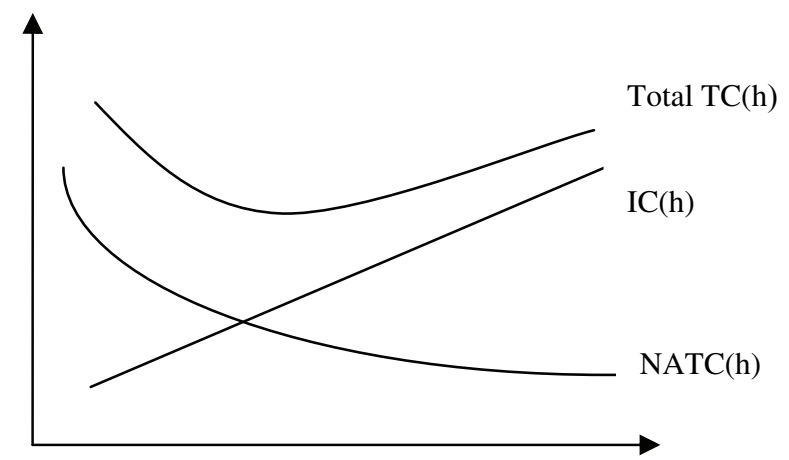

$\mathrm{h}$

Source: Authors.

Equations (3) and (4) thus represent how the GATCs are affected by the various aid transaction characteristics, over a single period, without taking into account that aid transfers may occur over several periods. Still, from these static equations, one may already draw an important conclusion: because (per definition) the aid relationship is always characterised by uncertainty (cf. the principal-agent theory) and because, in most cases, donors value at least some asset specificity, any aid transaction necessarily encompasses some NATCs.

Furthermore, in order to understand which aid modality is preferable, one should be aware that aid transactions generally occur over several periods (that is, in the language of TCE, with a certain frequency). For instance, a one-shot project may be implemented during one or a few months, whereas the development of a sector requires continuous interaction over many years (high frequency). When taking account of frequency in our model, where $t=1, \ldots, T$, one should be aware that the different transaction characteristics are most likely to influence each other. More specifically, it is reasonable to assume that harmonisation progressively enables the reduction of uncertainty through sharing information and building trust and common understanding between partners. Therefore, we assume that $\mathrm{u}_{t+l}$ is decreasing in $h\left(\delta u_{t+l} / \delta h_{t}<0\right)$ and, consequently, current investments in harmonisation reduce future NATCs: $\delta N A T C_{t+l} / \delta h_{t}$ $<0$. 


\subsection{Minimising aid transaction costs}

When assuming that aid effectiveness depends on transaction costs, two questions really matter: (i) is it possible to reduce transaction costs in the current framework; and (ii) could another aid modality do better? For instance, it is worth wondering whether shifting from a project approach to a PBA could improve aid effectiveness by decreasing transaction costs. It seems straightforward that a shift to a PBA should be made only if the associated reduction in NATCs at least compensates for the additional ICs incurred in creating the necessary conditions for alignment and harmonisation. In other words, one should compare the net present value (NPV) of the two proposed aid modalities, including additional IC and NATC savings due to a shift in aid modality. This is represented in equation (6):

$$
\sum_{t=1}^{T}\left\{\frac{I C_{t}(h)+N A T C_{t}\left(s, u, h_{t}, h_{t-1}\right)}{(1+r)^{t}}\right\}(P B A) \leq \sum_{t=1}^{T}\left\{\frac{I C_{t}(h)+N A T C_{t}\left(s, u, h_{t}, h_{t-1}\right)}{(1+r)^{t}}\right\}(\text { projects })
$$

with $r$ standing for the discount rate, $I C_{t}(h)$ being increasing in $h$ while $N A T C_{t}$ is decreasing in both $h$ and $h_{t-1}$ and increasing in $u$ and $s$. In this dynamic model, harmonisation plays a double role in reducing NATCs. First, over a single period, one may reasonably assume that the more harmonisation, the less transaction costs are necessary to manage the aid relationship, but over several periods, we have argued that harmonisation enables us to build capacities, trust and common systems that can further reduce uncertainty, so that the curve of NATCs will probably decrease in a sharper way with harmonisation, as illustrated in Figure 3 below. If this assumption is valid, contrary to the static model where harmonisation was not desirable beyond a certain point, we now observe that the more harmonisation (and related efforts and system strengthening), the less long-term transaction costs.

Figure 3: Likely evolution of transaction costs with harmonisation (dynamic model)

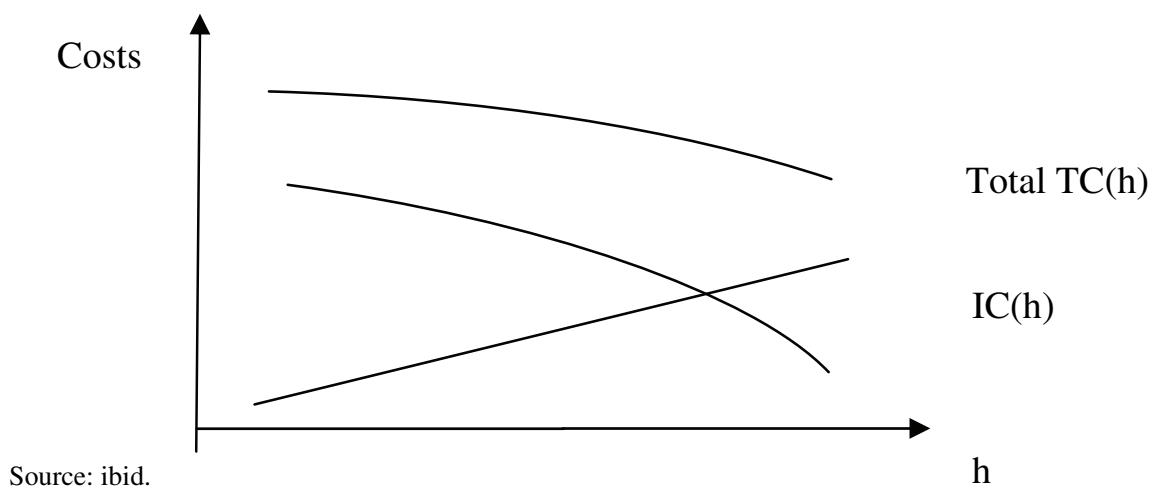


This simple model does not resolve the measurement problem of aid transaction costs: we do not put forward any other option than assessing them using proxy indicators. Yet, our model enables to assess how transaction costs are influenced by the transaction's characteristics, and formalises the difference between investment costs and net aid transaction costs. Therefore, it proposes to shift the effort from measuring transaction costs to assessing the value of different aid modalities according to the characteristics of the transaction. Equation (6) also illustrates the fact that if uncertainty and asset specificity are high, it is less likely that the change from a project approach to a PBA or budget support might compensate for the required investment costs. Similarly, if a PBA is adopted but donors lag behind in harmonising procedures, the expected benefits in reducing NATCs may not be sufficient to compensate for the investment costs. This supports anecdotal evidence indicating that the reduction of aid transaction costs after a change to budget support or PBA may not be as high as expected, at least in the beginning of the process. Hence the utility of our dynamic model that enables taking account of the long-term effects of investment costs (harmonisation) over transaction characteristics.

To sum up, transaction costs are ineluctable and inherent in the aid transaction. Investment costs are especially high when setting up a new aid modality, while NATCs are a consequence of imperfect information and the risk of opportunism (remember the behavioural hypotheses outlined in Sub-section 3.1). One should also remember that, when assessing the evolution of aid transaction costs, these often occur over several periods/years, so that it is important to evaluate their potential change on a longer time horizon. The model presented above enables us to render interesting features of the evolution of aid transaction costs according to the context and transaction characteristics. The main conclusions are summarised in Box 1.

\section{Box 1: Evolution of aid transaction costs and impact of the choice of an aid modality according to the transaction characteristics}

- NATCs increase when asset specificity is high, that is, when donors are not perfectly aligned with the recipient's policies and require some guarantee over the intended use of aid; in such a case, a project may be more cost-effective than a PBA.

- Uncertainty, which is notably due to information asymmetry between partners, raises NATCs; yet some ICs (for instance in the context of increased co-ordination and harmonisation between donors) may help decrease future uncertainty, and therefore subsequent NATCs; thus, the costs of setting up a PBA may be recovered after some time.

- Harmonisation has two opposite effects on transaction costs: it is likely to increase ICs since it requires setting up new ways of working together; but it presumably reduces the NATCs borne by the recipient government (the effect on the NATCs borne by donors is not straightforward); hence, the decision to shift to a PBA may be influenced by comparing these two types of costs.

- Frequency should also influence the choice of an aid modality because when the interaction between donors and the recipient government is frequent (for instance, long-term development programmes in the health or education sectors), ICs incurred to manage the relationship (for example, to set up a PBA) are expected to be recovered after some time, so that their impact on the reduction of NATCs will be more consequent, while one-shot interventions (for example, the construction of a unique facility) are probably better managed through a project. 


\section{Conclusion}

The Paris Agenda aimed at enhancing aid effectiveness was designed as a way of responding to the project-approach deficiencies, especially in a context of increasing donor fragmentation. Among other objectives, the Paris Agenda aims to reduce the transaction costs associated with aid delivery by aligning domestic programmes and systems, and by using new financing and management modalities, such as PBA/SWAp and budget support.

Recognising that the concept of aid transaction costs - even if commonly used by practitioners - has hardly been defined or measured, this article aims to develop a theoretical background to the concept by analysing it in relation to Transaction Cost Economics. The definition of aid transaction costs put forward rests on the concept of opportunity cost, and emphasises the fact that 'true' transaction costs are 'net' costs that is, they should not take account of 'investments' activities adding value to the outcomes of aid. We thus propose an analytical framework that allows comparing how they vary with different aid modalities, according to the context and characteristics of the aid transaction.

The minimisation of transaction costs is often advanced as an important aspect of aid effectiveness. However, our definition and the model above help to explain that the optimal aid modality (governance structure) depends on the characteristics of the transaction - for example, on the relation between a particular donor and the recipient government, and their respective preferences as to the allocation of the aid. The optimal governance structure may still generate a lot of costs (at least in the short run) and is likely to change if the characteristics of the transaction also change. In particular, the investment costs associated with a PBA can play an important role in reducing information asymmetry and in bringing donors' and government's preferences closer to each other. Yet, it is probably mistaken to adopt a PBA if donors are not ready to harmonise their procedures or are not numerous from the start. Therefore, the minimisation of 'apparent' aid transaction costs should not be an end in itself. For instance, if donors really disagree with the development programme of the recipient government, which leads to high asset specificity and the need to set up guarantees for the utilisation of the aid, the project approach could be preferred. Note also that donors are likely to be heterogeneous, so that it may be worth setting up a PBA (with increased co-ordination and harmonisation) for a number of 'traditional' donors, while some specific donors might do better continuing with the project approach.

In conclusion, this article demonstrates that Transaction Cost Economics is an assessment of the conditions under which new aid modalities (such as PBAs) are likely to reduce transaction costs and henceforth improve aid effectiveness.

first submitted December 2010 final revision accepted August 2011 


\section{References}

Acharya, A., Fuzzo de Lima, A., and Moore, M. (2006) 'Proliferation and Fragmentation: Transaction costs and the value of aid'. Journal of Development Studies 42 (1): 1-21.

Allen, D. W. (1991) 'What Are Transaction Costs?' Research in Law and Economics 14: $1-18$.

Amis, P., Green, L., and Hubbard, M. (2005) 'Measuring Aid Costs: What Has Been Learnt and What Still Needs to be Learnt', Public Administration and Development 25 (5): 373-8.

Arrow, Kenneth J. (1969) 'The Organization of Economic Activity: Issues pertinent to the choice of market versus nonmarket allocation', in The Analysis and Evaluation of Public Expenditure: The PPB System. Vol. 1. Washington, DC: US Government Printing Office.

Bourguignon, F. and Sundberg, M. (2007) 'Is Foreign Aid Helping? Aid Effectiveness: Opening the Black Box', American Economic Review 97 (2): 316-21.

Burnside, C. and Dollar, D. (2000) 'Aid, Policies, and Growth', American Economic Review 90 (4): 847-68.

Coase, R. (1961) 'The Problem of Social Costs', Journal of Law and Economics 3 (1): 1-44.

Coase, R. (1937) 'The Nature of the Firm', Economica 4 (16): 386-405.

Department for International Development (DFID) (2004) Poverty Reduction Budget Support. DFID Policy Paper. London: DFID.

Devarajan, S., and Swaroop, V. (1998) The Implications of Foreign Aid Fungibility for Development Assistance. Policy Research Working Paper No. 2022. Washington, DC: World Bank.

Dyer, K. (2005) The Cost of Poverty: Transaction Costs and the Struggle to Make Aid Work in the Education Sector in Tanzania. Human Development Report Office Occasional Paper. Arusha: IMG/United Nations Development Programme.

Easterly, W., Levine, R. and Roodman, D. (2003) New Data, New Doubts: A Comment on Burnside and Dollar's 'Aid, Policies, and Growth' (2000). NBER Working Paper 9846. Cambridge, MA: National Bureau of Economic Research.

EuropeAid (2007) Support to Sector Programmes Covering the Three Financing Modalities: Sector Budget Support, Pool Funding and EC Project Procedures. Tools and Methods Series, Guidelines No. 2. Brussels: European Commission.

European Commission (EC) (2007) 'Guidelines on the Programming, Design and Management of General Budget Support', in Aid Delivery Methods. Brussels: EC.

Foster, M. and Leavy, J. (2001) The Choice of Financial Aid Instruments. Working Paper 158. London: Overseas Development Institute.

High-Level Forum on Aid Effectiveness (2005) Paris Declaration on Aid Effectiveness: Ownership, Harmonisation, Alignment, Results and Mutual Accountability. Paris: OECD.

High-Level Forum on Harmonization (2003) Rome Declaration on Harmonization (25 February). Paris: OECD. 
IDD and Associates (2006) Joint Evaluation of General Budget Support 1994-2004: Synthesis Report. Birmingham: International Development Department, University of Birmingham.

Jobin, D. (2008) 'A Transaction Cost-Based Approach to Partnership Performance Evaluation', Evaluation 14 (4): 437-65.

Killick, T. (2004) 'Politics, Evidence and the New Aid Agenda', Development Policy Review 22 (1): 5-29.

Knack, S. and Rahman, A. (2004) Donor Fragmentation and Bureaucratic Quality in Aid Recipients. Policy Research Working Paper 3186. Washington, DC: World Bank.

Lavergne, R. and Alba, A. (2003) CIDA Primer on Programme-Based Approaches. Ottawa: Canadian International Development Agency (CIDA).

Lawson, A. (2009) 'Evaluating the Transaction Costs of Implementing the Paris Declaration'. Concept Paper submitted by Fiscus Public Finance Consultants to the Secretariat for the Evaluation of the Paris Declaration, November.

Martens, B.; Mummert, U.; Murrell, P. and Seabright, P. (2002) The Institutional Economics of Foreign Aid. Cambridge: Cambridge University Press.

Martínez, J. (2006) Implementing a Sector-wide Approach in Health: The case of Mozambique. Technical Approach Paper. London: HLSP Institute.

North, D. (1990) Institutions, Institutional Change and Economic Performance. Cambridge: Cambridge University Press.

Organisation for Economic Co-operation and Development (OECD) (2006) Harmonising Donor Practices for Effective Aid Delivery - Vol. 2: Budget Support, Sector Wide Approaches and Capacity Development in Public Financial Management. DAC Guidelines and Reference Series. Paris: OECD.

Organisation for Economic Co-operation and Development (OECD) (2005) Survey on Harmonisation and Alignment: Progress in Implementing Harmonisation and Alignment and 14 Partner Countries. Paris: OECD, Development Assistance Committee.

Organisation for Economic Co-operation and Development (OECD) (2003) Harmonising Donor Practices for Effective Aid Delivery. DAC Guidelines and Reference Series. Paris: OECD.

Paul, E. (2006) 'A Survey of the Theoretical Economic Literature on Foreign Aid', Asian-Pacific Economic Literature 20 (1): 1-17.

Paul, E. (2002) 'The Poverty Reduction Strategy Paper (PRSP): Incarnation of a new development aid paradigm or a SAP sub-product? Review of the PRSP process in Benin'. Paper presented at International Conference on 'Africa and the Development Challenges of the New Millennium', organised by TWN Africa / Codesria, Accra, 23-26 April.

United Nations Development Programme (UNDP) and Department for International Development (DFID) (2000) Aid Transaction Costs in Vietnam. Final Report. Hanoi: UNDP and DFID.

United Nations International Conference on Financing for Development (2002) Monterrey Consensus on Financing for Development, Monterrey, 18-22 March.

Vandeninden, F. (2005) 'Une analyse de la performance des modes de gestion de l'aide au développement: L'approche sectorielle permet-elle de réduire les coûts de 
transaction liés à la gestion de l'aide?'. Bachelor thesis, Liège: Université de Liège, HEC-Ecole de Gestion.

Watt, P. (2005) Transaction Costs in Aid: Case Studies of Sector Wide Approaches in Zambia and Senegal. UNDP Human Development Report Office Occasional Paper. New York: UNDP.

Williamson, O. E. (1993) The Economic Analysis of Institutions and Organisations in General and with respect to Country Studies. OECD Working Paper 133. Paris: OECD.

Williamson, O. E. (1985) The Economic Institutions of Capitalism: Firms, markets, relational contracting. New York: Free Press.

World Bank (1998) Assessing Aid: What Works, What Doesn't, and Why. Policy Research Report. Oxford and New York: Oxford University Press for the World Bank. 